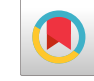

\title{
Injury-related Pediatric Mortality in Shiraz, Iran: A Community-based Survey
}

\author{
Elham Vahhab ${ }^{1}$, Saeid Gholamzadeh ${ }^{2}$ and Mohammad Zarenezhad ${ }^{3, *}$ \\ ${ }^{1}$ Student Research Committee, Shiraz Medical School, Shiraz University of Medical Sciences, Shiraz, Iran \\ ${ }^{2} \mathrm{MD}$, Iranian Legal Medicine Research Center, Legal Medicine Organization, Tehran, Iran \\ ${ }^{3} \mathrm{MD}$, PhD, Iranian Legal Medicine Research Center, Legal Medicine Organization, Tehran, Iran \\ "Corresponding author: Mohammad Zarenezhad, MD, PhD, Iranian Legal Medicine Research Center, Legal Medicine Organization, Tehran, Iran. Tel: +98-9173130250, E-mail: \\ zarenezhad@hotmail.com
}

Received 2018 April 24; Revised 2018 May 25; Accepted 2018 May 26.

\begin{abstract}
Background: Childhood and adolescent injuries are among the most significant health system hazards, especially in developing countries including Iran. In this report, we evaluated the main characteristics of all cases of pediatric injury-related mortality in Shiraz in a 5 - year - period.

Methods: This cross - sectional study comprised all injury- related deaths in children and adolescents up to 18 years of age, from September 2011 to September 2016 in Shiraz, Iran. The required information about demographic factors including age, sex, cause of death, the manner and location of death and time period between injury and death was collected for all the cases.

Results: There were 485 cases ( $66 \%$ male) with mean age of $8.7 \pm 5.9$ years. The crude mortality rate was 21.6 per 100000 population in each year. Infants had the lowest rate during the first year (6.4\%) and children between 1 to 4 years had the highest rate of death (28.7\%). Accident was the most common manner of death occurring in 393 (81.0\%) followed by suicide in 58 (12.0\%) decedents. Mortality due to electrical injury, traffic accidents, falling down, burns, drowning and blunt trauma were more common in the 1- 4 years age group. Suffocation, poisoning, work accident and firearm were the most common cause of death in 15 - 18 year - old children. Except for aspiration, firearm and penetrating trauma, all other causes were more common in boys. The most common location of death was at the scene of injury ( $48 \%$ ). The majority of deaths occurred in the first 6 hours after injury (311 cases, 64.1\%).

Conclusions: Most cases of pediatric injury - related mortality were secondary to preventable injuries and occurred during the first 6 hours and before arriving at the hospital. Thus, injuries should be considered as one of the priorities of the health system and preventive measures such as educating the caregivers regarding these events should be emphasized.
\end{abstract}

Keywords: Death, Child, Adolescent, Pediatric, Injury, Accident

\section{Background}

According to WHO, every human being younger than 18 years of age is a child (1). Childhood injury is an important burden on the health system globally (2). It is one of the leading causes of pediatric mortality (1) that brings about at least 875000 childhood deaths worldwide in each year (3). In fact, most cases of pediatric mortality in children older than 1 year are due to injuries (3). While more than 95\% of all children and adolescents injury - related deaths are in countries with low- or middle - income, injuries are responsible for about $40 \%$ of deaths in those $1-18$ years old in high - income countries (4). The most common causes of injuries include road traffic injuries and drowning $(3,5$, 6).

Iran is a developing country with a relatively young population. Based on a report from the Statistical Center of Iran, about 24.5 million people (31\%) were under 19 years of age in 2016 (7). In addition to being a global problem, injuries are considered a significant health problem in Iran (2). As a matter of fact, they were the most important pediatric related health problem in Iran in 2003 and 2005 (8). In addition, in the first Iranian national burden of disease study in 2003, the second - greatest disability-adjusted life year rate in children younger than 4 years was attributed to injuries (9). Considering different causes of injuries, traffic accident is the most common cause of pediatric injury - related deaths in Iran $(8,10)$.

There are reports regarding pediatric injury - related mortality in different parts of Iran $(2,10)$; however, there were only a few studies on specific injury - related deaths in Shiraz (11-13). Nonetheless, to our knowledge, no extensive study on pediatric injury - related mortality has been done in Shiraz. In spite of the significant population of 
children, there is not enough information about different injury - related deaths. Therefore, in this study we evaluated the main characteristics of all cases of pediatric injury - related mortality in Shiraz in a 5 -year - period to highlight its burden on health system and facilitate improvement of preventive measures.

\section{Methods}

This cross - sectional study included all injury - related deaths in children and adolescents up to 18 years of age between September 2011 and September 2016 in Shiraz, Iran. Shiraz is the most populated city in the southern half of Iran (14) with a population of about 1.5 million in 2015 (15). Shiraz Legal Medicine Organization Registry was used as the data source for this study. According to Iranian law, the exact cause of death in all injury related cases or accidents must be determined by an autopsy (16). All such deaths in Shiraz are referred to the legal medicine center in this city and are included in the database of Shiraz Legal Medicine Organization Registry. This research was reviewed and approved by the Ethics Committee of Shiraz University of Medical Sciences and was performed in accordance with the Declaration of Helsinki.

Mortality caused by congenital diseases, infections, and other natural causes were excluded from this study. Also, cases that were referred to Legal Medicine Organization from other cities in the Fars province were excluded. Furthermore, we did not take into account cases with an unclear cause of death even after an autopsy in our study.

In order to gather the required information, we referred to the legal medicine center of Fars province in Shiraz and obtained a license to protect the identity of the deceased person. Information was extracted from the archived files available through basic data from informatics and IT engineering centers of legal medicine organization. Whenever needed, the database of the Department of Health of Shiraz University of Medical Sciences was accessed for complementary data. For any case included, a trained researcher collected the required information on demographic factors including age, sex, autopsy documented cause of death, the manner and location of death, and time period between injury and death. Detailed pathology and toxicology reports were also reviewed for each case, if applicable. They were categorized into 5 age groups: $<1,1-4,5-9,10-14$ and 15 18 years. Also, the final cause of death was divided into 13 groups: suffocation, aspiration, electrical injury, traffic accident, falling down, burns, drowning, blunt trauma, work accident, firearm, poisoning, natural accident, and penetrating trauma. Manner of death was categorized into 3 groups: accident, suicide, and homicide. The accident group was unintentional while suicide and homicide groups were considered as intentional injuries. Accident related information consisted of cause of death, location of death, and time of interval between injury and death. The crude mortality rate was calculated by dividing the average number of deaths by the average total pediatric population of Shiraz in the 5 years of study period multiplied by 100000 .

We performed the statistical analysis using the SPSS base 21 (SPSS Inc, www.ibm.com/software/analytics/spss/products/statistics) statistical software package. Results for quantitative variables are shown as mean and standard deviation and results for categorical variables are shown with frequencies and percentages. We used Independent samples $t$ test to compare mean age between males and females. Chi - square test and Fisher's exact test were used to make comparisons between categorical or proportional variables. $\mathrm{P}$ $<0.05$ was considered to be statistically significant.

\section{Results}

In this study, we found 485 cases of pediatric injury related deaths (66\% male, sex ratio of almost 1.9:1). Considering the mean pediatric population of 448721 children in Shiraz in the study period, the crude mortality rate was 21.6 per 100000 population in each year (27.8 and 15.1 per 100000 in each year for males and females, respectively). Also, the crude mortality rate for the pediatric population younger than 15 years in our study was 21.5 per 100000 population in each year. The leading cause of death in this report was traffic accident with 227 (46.8\%) decedents. The trend of crude and sex - specific mortality rates in different years of the study period is shown in Figure 1. Specific mortality rates based on age and sex are shown in Table 1.

\begin{tabular}{|c|c|c|}
\hline & \multicolumn{2}{|c|}{ Specific Mortality Rates } \\
\hline & Male & Female \\
\hline \multicolumn{3}{|l|}{ Age (years) } \\
\hline$<1$ & 27.6 & 23.7 \\
\hline $1-4$ & 37.5 & 20.9 \\
\hline $5-9$ & 20.0 & 14.5 \\
\hline $10-14$ & 24.6 & 11.4 \\
\hline $15-18$ & 30.9 & 12.5 \\
\hline $\mathbf{P}^{\mathbf{a}}$ & \multicolumn{2}{|c|}{0.4} \\
\hline
\end{tabular}

${ }^{\mathrm{a}} \mathrm{P}$ calculated by $\chi^{2}$ test.

The mean age of the cases was $8.7 \pm 5.9$ years (range: 8 days - 18 years). There was no significant difference in 


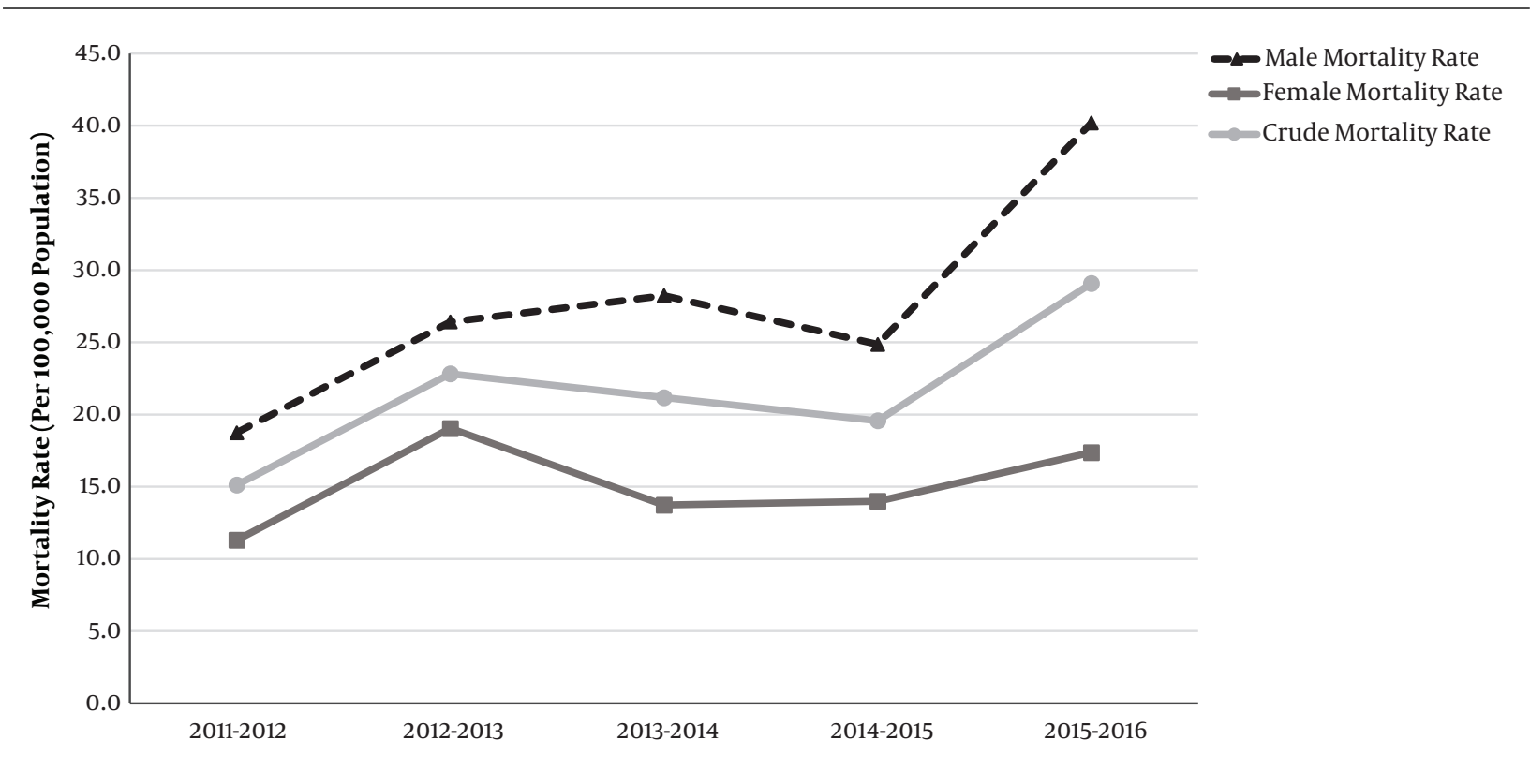

Figure 1. Trend of Crude and Sex - specific Pediatric Injury - related Mortality Rates in Shiraz, Iran

the mean age between males and females in this study (9.1 \pm 6.0 and $8.1 \pm 5.7$, respectively; $\mathrm{P}=0.1$ ). Also, no significant difference was observed between males and females regarding the age groups $(\mathrm{P}=0.2)$. The 1 - 4 years age group had the highest proportion (28.7\%) while the $<1$ year age group had the lowest proportion of injury related death (6.4\%). More details about age and sex distribution of the cases are listed in Table 2.

Table 2. Age and sex Distribution of the Pediatric Injury - related Deaths in Shiraz, Iran

\begin{tabular}{cccc}
\hline & \multicolumn{3}{c}{ Sex, N(\%) } \\
\cline { 2 - 4 } & Male $(\mathbf{N}=\mathbf{3 2 0})$ & Female $(\mathbf{N}=\mathbf{1 6 5})$ & Total $(\mathbf{N}=\mathbf{4 8 5})$ \\
\hline Age (years) & & & \\
$<1$ & $17(5.3)$ & $14(8.5)$ & $31(6.4)$ \\
$1-4$ & $91(28.4)$ & $48(29.1)$ & $139(28.7)$ \\
$5-9$ & $58(18.1)$ & $40(24.2)$ & $98(20.2)$ \\
\hline $10-14$ & $70(21.9)$ & $31(18.8)$ & $101(20.8)$ \\
\hline $\mathbf{P}^{\mathbf{a}}$ & $84(26.3)$ & $32(19.4)$ & $116(23.9)$ \\
\hline
\end{tabular}

${ }^{\mathrm{a}} \mathrm{P}$ calculated by $\chi^{2}$ test.

According to Table 3, there was a significant difference in the cause of death between different age groups $(\mathrm{P}<$ 0.001). Most cases of suffocation were in 15 - 18 years followed by 10 - 14 years age groups; however, all cases of aspiration had an age range of less than 1 year followed by
1 - 4 years. In deceased cases secondary to electrical injury, traffic accidents, falling down, burns, drowning, and blunt trauma, children aged 1 - 4 years were predominant. However, children aged 15 - 18 years had the highest mortality due to work accidents and firearms. Considering deaths secondary to poisoning, the 15 - 18 years age group had the highest number of mortality followed by 1 - 4 years age group.

Furthermore, there was a significant difference in the cause of death between males and females, as is illustrated in Table $3(\mathrm{P}<0.001)$. Except for aspiration, firearm and penetrating trauma, all other causes of death were more common in boys as compared to girls. All decedents secondary to a work accident and the only case of natural accident that occurred due to lightning strike were male. Also, almost all deaths due to electrical injury, drowning, and blunt trauma were in boys. Traffic accident was the most common cause of death in both genders followed by drowning and poisoning in boys and girls, respectively.

Table 4 shows a significant difference in the distribution of death manner and location by considering the causes $(\mathrm{P}<0.001)$. The most common manner of death in this study was accident with 393 cases (81.0\%), followed by suicide with 58 decedents (12.0\%). All deaths were secondary to aspiration, electrical injury, work, and natural accident and also most cases of poisoning, traffic accident, falling down, burns, and drowning occurred in an accidental manner. However, most deaths due to suffocation were considered as suicide; in fact, the most common method 


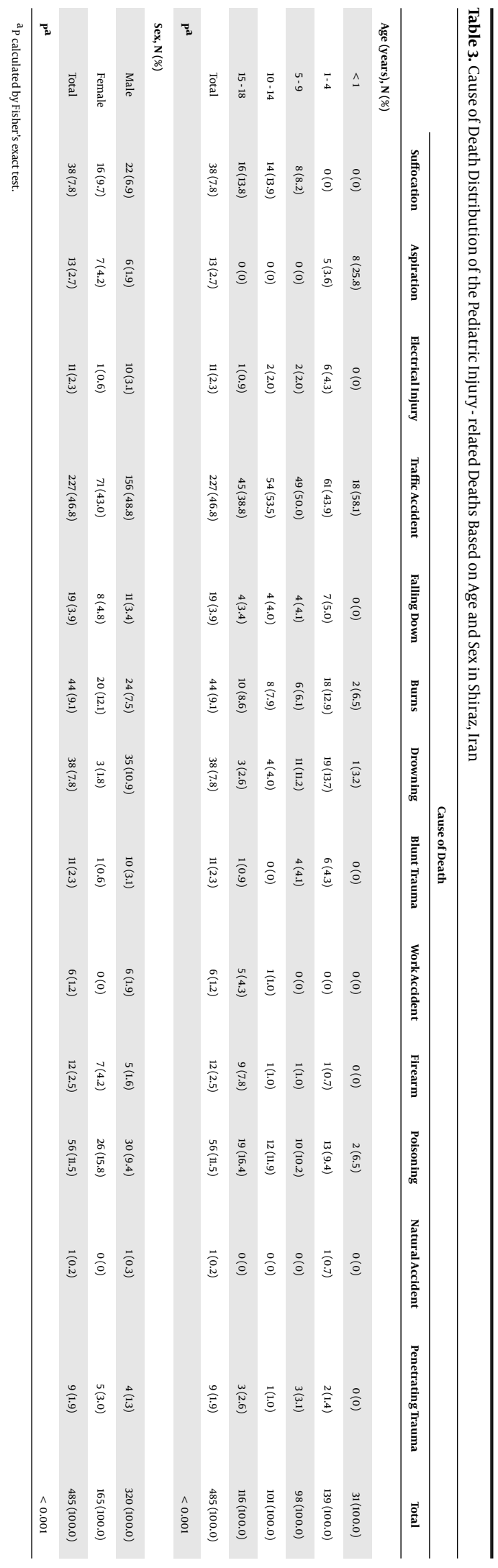

used in suicidal deaths in this study was hanging, which resulted in suffocation. Moreover, homicide was the most common manner in decedents secondary to firearm, blunt trauma, and suffocation.

The two most common locations of death were at the scene and at the hospital, respectively. By considering the causes of death, most cases in all groups passed away at the scene except for traffic accident, burns, and blunt trauma.

As shown in Table 5, a significant difference was observed in the time period between accident and death considering the different groups $(\mathrm{P}<0.001)$. About $64 \%$ deaths occurred during the first 6 hours and about 80\% during the first 24 hours after the injury.

\section{Discussion}

Our results confirmed that the most common age of pediatric injury - related mortality was 1 - 4 years and it was more common in boys. Traffic accident was the most prevalent cause and accidental injury was the most common manner of death. Most decedents passed away at the scene and the majority of cases died in the first 6 hours following the injury.

In our study, the pediatric crude mortality rate was 21.5 per 100000 population in each year for children younger than 15 years of age. However, Naghavi et al., reported a pediatric injury - related mortality rate of 35 per 100000 population in their study for the same age group, which was based on Iran's death registration data of 2005 (2). Although this difference may be explained in part by measuring crude mortality rate in different populations, it may also indicate the effect of the health system's effort to reduce the injury - related deaths in Shiraz during a 10 - year - period.

In this study, children with 1 - 4 years of age had the highest injury - related mortality. This is similar to a report from northern Iran with the highest rate of trauma (43\%) in children under 5 years (17). Also, studies from Sub - Saharan Africa, Japan, and the United Arab Emirates report a high rate of injury-related mortality in 1 - 4 year old children $(4,18,19)$. Absence or neglect of the caregiver and insufficient knowledge, curiosity, and special physiology of children younger than 5 years of age might have a role in higher injury - related mortality of this age group $(1,18)$.

The lowest proportion of injury - related death in infants is in concordance with studies from Qatar and China $(6,20,21)$. This finding may be partly due to inability of an infant with less than 1 year of age to walk and to have a dangerous interaction with the environment.

Consistent with other reports from Iran (2), Qatar (6), India (22), and South Africa (5), traffic accident was the main cause of mortality in all age groups in our study. 

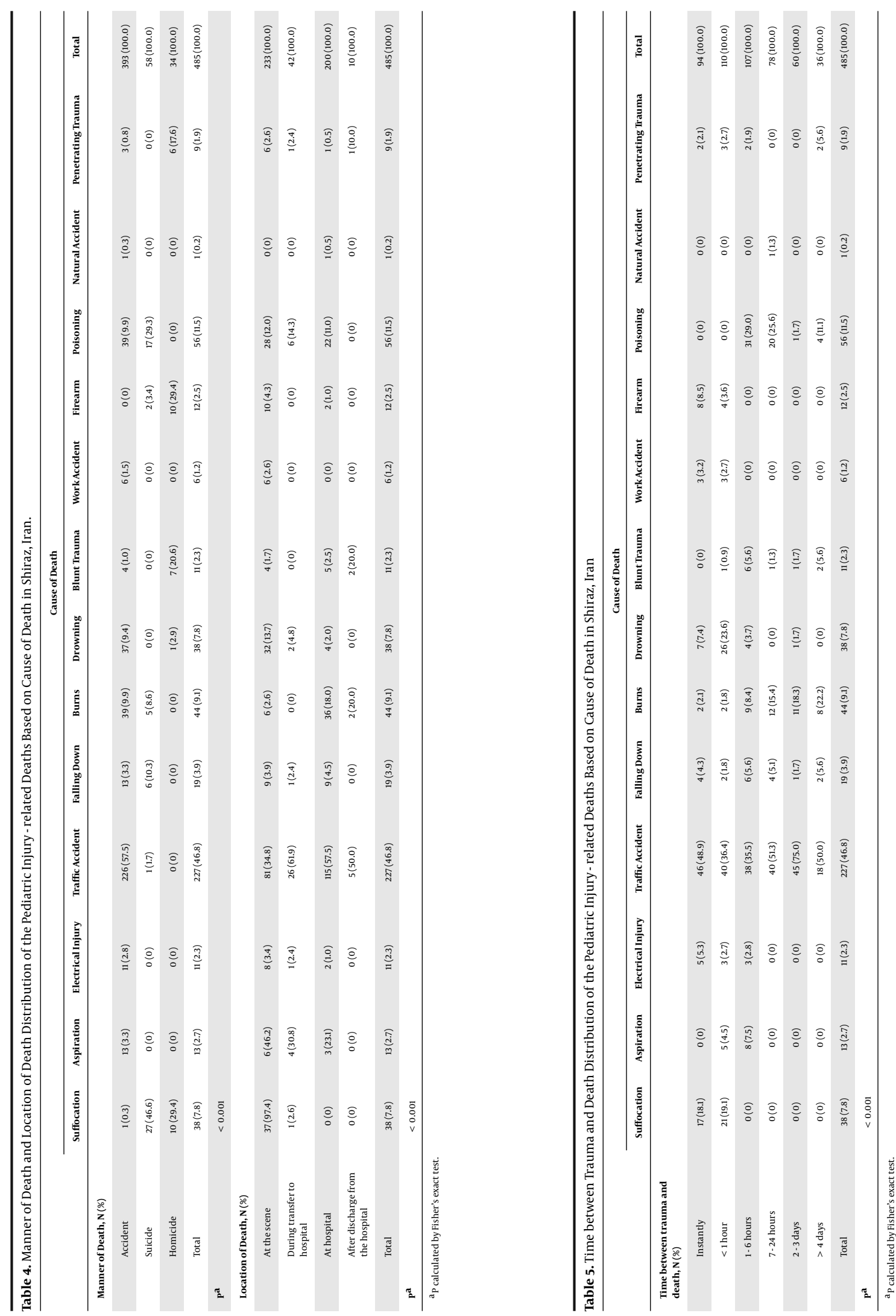
Another study in Eastern Mediterranean region (EMR), including Iran, revealed that the leading cause of death due to unintentional injuries among children was road traffic injuries (23). According to the WHO Global Burden of Disease project, road traffic deaths in Africa and EMR are high and children's deaths in these events were estimated $21 \%$. Also, almost $30 \%$ of all injury related deaths were among children. It is predicted that by the year 2030, road traffic injuries will be the fifth leading cause of deaths worldwide (1). Non - standard safety designs of vehicles and roads (23) and failure to take safety measures (16) are two important reasons for the high rate of traffic accidents. Thus, traffic accident morbidity and mortality imposes a heavy burden on the public health system globally, especially in developing countries like Iran, and requires prioritization $(16,23$, 24).

In our study, mortality due to traffic accidents was more common in $1-4$ years age group. This might partly be due to insufficient knowledge or the failure of caregivers of younger children to take safety measures such as using the child safety seat in the car in Iran as a developing country (16). On the other hand, small children are too short to be visualized by drivers as pedestrians (25) and their sensory facilities (visual and auditory) are not fully developed (1). Also, children are in a growing state and their relative softness makes them physically more vulnerable to the impact of injury as compared to adults (1).

In the present study, most cases of suffocation were in the age range of $10-18$ years. This is similar to reports from South Africa, San Diego, and Lorestan province of Iran (3, 5, 10). This is possibly due to enough knowledge and ability of such children to perform hanging. On the contrary, our results showed that all cases of aspiration were accidental in infants and children up to five years. This is in concordance with reports from Brazil and Japan $(4,26)$. Also, airway obstruction was the most common cause of injury-related mortality in a report from Tehran (27). These findings are usually due to inadequate knowledge and the curiosity of these small children. Also, it can be explained in part by the tendency of children at this age to put different objects into their mouths (28) and inability to chew foods adequately that increases the risk of aspiration (29).

Deceased cases due to electrical injury, falling down, burns, and drowning were also more common in smaller children similar to reports from Lorestan and South Africa $(5,10)$. The exploratory nature of children with less than 5 years of age (30) and their lack of awareness to avoid high risk behaviors are probably the explanation for these findings (31).

Similar to our results, reports from Brazil and Lorestan showed that children older than 15 years had the highest mortality due to firearms $(10,26)$. This may be explained by higher rates of retaliatory attitudes (32) and easier ac- cess to firearms (33) in children of this age category. Therefore, educating the families regarding safe storage of the firearms is very important.

The greatest mortality rate secondary to poisoning was observed in children aged 15 - 18 years followed by 1 - 4 years, which is similar to the studies in Lorestan and South Africa $(5,10)$. In another recent study from Shiraz, children aged 13 - 18 years had the highest hospital admissions due to poisoning (34). Although most of the deaths secondary to poisoning, especially in the younger children, are accidental (35), the higher rate of deaths due to poisoning in the 15 - 18 years age group is probably due to increased number of suicidal attempts in this age group (36). Thus, educating the parents regarding safe storage of toxic substances and medications as well as taking care of teenager's mental health should be taken into account as one of the priorities of the health system.

A male predominance was observed in all age categories regarding pediatric mortality in this study. These results are in accordance with other reports from Iran, Japan, India, San Diego, and Eastern Mediterranean Region (2-4, $22,37)$. Curiosity and the impulsive nature of boys compared with girls can justify these findings (3). However, it is astonishing that girls had a higher number of firearm related mortality than boys, which might have happened following sexual abuse. This result is in contrast with other reports from the United States that show male predominance regarding firearm - related mortality $(38,39)$. Easy access to firearms (33) and presence of male with ethnic minorities who are at greater risk for firearm assault in the United States (38) may contribute to this gender discrepancy.

Most cases in this report were deceased in an accidental manner. This statement is in accordance with a study conducted in Tehran on childhood injuries (40) and the studies performed in San Diego (3) and South Africa (5). In our study, the second most common manner of death was suicide followed by homicide, which did not coincide with the last two studies. Intentional injuries including homicide and suicide accounted for $24.2 \%$ and $9.4 \%$ of deaths in San Diego (3) and 14\% and 7\% of deaths in South Africa (5) reports, respectively. The higher rate of homicidal - related mortality in these 2 studies is probably due to easier access to firearms, the most common means of firearm, in the United States and South Africa compared with Iran $(3,5)$. Most suicidal deaths in our study were performed by hanging, as previous studies in Shiraz (41) and in the South Africa report (5). Although these results show that most cases of injury-related deaths are due to preventable accidents, an increased proportion of pediatric suicidal deaths in Shiraz is an important public health problem that should be dealt with properly.

In most previous reports like our study, the majority 
of cases died at the scene $(3,26)$ in contrast to the Tehran study on children less than 5 years of age that most cases died at the hospital (27). This difference might be due to a lower age range of the Tehran study population with a lower risk of facing highly fatal injuries that kill the subject quickly at the scene. Also, in accordance with our finding, in the Brazil and San Diego reports, most cases died within the first 24 hours $(3,26)$. This might be due to the severity of events or it can be due to more vulnerability of children against injuries.

The main limitation to our study was its retrospective design. Also, lack of some information in Shiraz Legal Medicine Organization Registry database including a small number of families that may have buried their dead child directly without referring to Legal Medicine Organization and also occasional death with uncertain cause in the hospitals with no referral to Legal Medicine Organization. Therefore, a minor gap might be present in our result compared with the actual data. Further studies with prospective design that address these limitations are recommended.

In conclusion, pediatric and adolescent death imposes a high economical and emotional burden on society. Pediatric injury - related mortality in Shiraz was more common in boys and in 1 - 4 years age group. Traffic accident was the most prevalent cause and accident was the most prevalent manner of death. Most of the injury - related mortalities are due to preventable injuries. Therefore, preventive measures such as educating the caregivers and using protective devices such as seat belt, helmet, and child safety seat are highly effective and recommended. Although the clinical management of trauma patients has been improved in recent decades, better concordance between systems involved in trauma prevention and management is necessary to reduce the burden of disease. Also, injury prevention should be considered as one of the priorities of the health system in order to minimize the rate of injuries and injury-related mortality with appropriate plans and actions.

\section{Footnote}

Funding/Support: The present article was extracted from the thesis written by Elham Vahhab and was financially supported by Vice Chancellor for Research in Shiraz University of Medical Sciences [grant number 95-01-01-12814].

\section{References}

1. Peden M, Oyegbite K, Ozanne-Smith J, Hyder AA, Branche C, Rahman AF. World report on child injury prevention. Geneva (Switzerland): World Health Organization and UNICEF; 2008.
2. Naghavi M, Pourmalek F, Shahraz S, Jafari N, Delavar B, Motlagh ME. The burden of injuries in Iranian children in 2005. Popul Health Metr. 2010;8:5. doi: 10.1186/1478-7954-8-5. [PubMed: 20356350]. [PubMed Central: PMC2853502].

3. Fraga AM, Fraga GP, Stanley C, Costantini TW, Coimbra R. Children at danger: injury fatalities among children in San Diego County. Eur J Epidemiol. 2010;25(3):211-7. doi: 10.1007/s10654-009-9420-1. [PubMed: 20084430]. [PubMed Central: PMC2836467].

4. Sekii H, Ohtsu T, Shirasawa T, Ochiai H, Shimizu T, Kokaze A. Childhood mortality due to unintentional injuries in Japan, 2000\&\#8211;2009. Int J Environ Res Public Health. 2013;10(2):52840. doi: 10.3390/ijerph10020528. [PubMed: 23364538]. [PubMed Central: PMC3635160].

5. Van den Ordel G, Du Toit-Prinsloo L, Saayman G. Childhood and adolescent fatalities at the Pretoria Medico-Legal Laboratory: 2005-2009. South African J Child Health. 2016;10(1):52. doi: 10.7196/SAJCH.2016.v10i1.1047.

6. Bener A, Hussain SJ, Ghaffar A, Abou-Taleb H, El-Sayed HF. Trends in childhood trauma mortality in the fast economically developing State of Qatar. World J Pediatr. 2010;7(1):41-4. doi: 10.1007/s12519-0100208-X.

7. Roudi F, Azadi P, Mesgaran M. Iran's Population Dynamics and Demographic Window of Opportunity. Stanford University; 2017. 27 p.

8. Imamura JH, Troster EJ, Oliveira CA. What types of unintentional injuries kill our children? Do infants die of the same types of injuries? A systematic review. Clinics. 2012;67(9):1107-16. doi: 10.6061/clinics/2012(09)20.

9. Naghavi M, Abolhassani F, Pourmalek F, Lakeh M, Jafari N, Vaseghi S, et al. The burden of disease and injury in Iran 2003. Popul Health Metr. 2009;7:9. doi:10.1186/1478-7954-7-9. [PubMed: 19527516]. [PubMed Central: PMC2711041].

10. Astaraki P, Mahmoudi G, Ahadi M, Almasi V. The reasons of death among children and adolescents in Lorestan Province, West of Iran, from 2007 to 2014. Int JMed Toxicol Forensic Med. 2016;6(2 (Spring)):6570.

11. Yadollahi M, Paydar S, Sabetianfard Jahromi G, Khalili H, Etemadi S, Abbasi $\mathrm{H}$, et al. Types and causalities in dead patients due to traumatic injuries. Arch Trauma Res. 2015;4(1). e26028. doi: 10.5812/atr.26028. [PubMed: 25798419]. [PubMed Central: PMC4360604].

12. Fallahzadeh MA, Abdehou ST, Hassanzadeh J, Fallhzadeh F, Fallahzadeh MH, Malekmakan L. Pattern of in-hospital pediatric mortality over a 3-year period at University teaching hospitals in Iran. Indian J Crit Care Med. 2015;19(6):311-5. doi: 10.4103/0972-5229.158257. [PubMed: 26195856]. [PubMed Central: PMC4478671].

13. Haghighat M, Moravej H, Moatamedi M. Epidemiology of Pediatric Acute Poisoning in Southern Iran: A Hospital-Based Study. Bull Emerg Trauma. 2013;1(1):28-33. [PubMed: 27162818]. [PubMed Central: PMC4771239].

14. Vakili V, Shojaei P, Shaye ZA, Bazaz MM. Cluster analytical approach to Lifestyle characteristics: A population based study in Shiraz, Iran. Electron Physician. 2016;8(5):2388-94. doi: 10.19082/2388. [PubMed: 27382449]. [PubMed Central: PMC4930259].

15. Honarvar B, Lankarani KB, Ghahramani S, Akbari M, Tabrizi R, Bagheri Z, et al. Satisfaction and Dissatisfaction Toward Urban Family Physician Program: A Population Based Study in Shiraz, Southern Iran. Int J Prev Med. 2016;7:3. doi: 10.4103/2008-7802.173793. [PubMed: 26941904]. [PubMed Central: PMC4755284].

16. Heydari ST, Hoseinzadeh A, Ghaffarpasand F, Hedjazi A, Zarenezhad M, Moafian G, et al. Epidemiological characteristics of fatal traffic accidents in Fars province, Iran: a community-based survey. Public Health. 2013;127(8):704-9. doi: 10.1016/j.puhe.2013.05.003. [PubMed: 23871394].

17. Yousefzadeh S, Hemmati H, Alizadeh A, Karimi A, Ahmadi M, Mohammadi H. Pediatric unintentional injuries in north of Iran. Iran JPediatr. 2008;18(3):267-71. 
18. Ruiz-Casares M. Unintentional childhood injuries in sub-Saharan Africa: an overview of risk and protective factors.J Health Care Poor Underserved. 2009;20(4 Suppl):51-67. doi: 10.1353/hpu.0.0226. [PubMed: 20168033].

19. Bener A, Hyder AA, Schenk E. Trends in childhood injury mortality in a developing country: United Arab Emirates. Accid Emerg Nurs. 2007;15(4):228-33. doi: 10.1016/j.aaen.2007.07.010.

20. Yin Z, Wu J, Luo J, Pak AW, Choi BC, Liang X. Burden and trend analysis of injury mortality in China among children aged 0-14 years from 2004 to 2011. BMJ Open. 2015;5(7). e007307. doi:10.1136/bmjopen-2014007307. [PubMed: 26137882]. [PubMed Central: PMC4499679].

21. Wang Y, Du M, Hao Z, Zhang H, Zhang Q, Hao W, et al. Causes of Death in Children Aged $<15$ Years in the Inner Mongolia Region of China, 2008-2012. Glob J Health Sci. 2016;8(9):56176. doi: 10.5539/gjhs.v8n9p76. [PubMed: 27157187]. [PubMed Central: PMC5064087 publication of this paper].

22. Kanchan T, Menezes RG. Mortalities among children and adolescents in manipal, southern India. J Trauma. 2008;64(6):1600-7. doi: 10.1097/TA.ob013e3180a032a1. [PubMed: 18545130].

23. Moafian G, Aghabeigi MR, Heydari ST, Hoseinzadeh A, Lankarani KB, Sarikhani Y. An epidemiologic survey of road traffic accidents in Iran: analysis of driver-related factors. Chin J Traumatol. 2013;16(3):140-4. [PubMed: 23735547].

24. Hamzeh B, Najafi F, Karamimatin B, Ahmadijouybari T, Salari A, Moradinazar M. Epidemiology of traffic crash mortality in west of Iran in a 9 year period. Chinese J Traumatol. 2016;19(2):70-4. doi: 10.1016/j.cjtee.2015.12.007.

25. Peymani P, Heydari ST, Hoseinzadeh A, Sarikhani Y, Hedjazi A, Zarenezhad M, et al. Epidemiological characteristics of fatal pedestrian accidents in Fars Province of Iran: a community-based survey. Chin J Traumatol. 2012;15(5):279-83. [PubMed: 23069098].

26. Fraga AM, Bustorff-Silva JM, Fernandez TM, Fraga GP, Reis MC, Baracat EC, et al. Children and adolescents deaths from trauma-related causes in a Brazilian City. World J Emerg Surg. 2013;8(1):52. doi: 10.1186/17497922-8-52. [PubMed: 24305495]. [PubMed Central: PMC3867624].

27. Delbarpourahmadi S, Tajoddini F, Ehdayivand F, Dehkordi BM, Farsar A, Torkamannezhad S. Studying deaths due to accidents in children with 1-59 months of age in Shahid Beheshti University in 2011-2012. Saf Improv Inj Prev. 2014;1(4):205-11.

28. Fraga Ade M, Reis MC, Zambon MP, Toro IC, Ribeiro JD, Baracat EC. Foreign body aspiration in children: clinical aspects, radiological aspects and bronchoscopic treatment.J Bras Pneumol. 2008;34(2):74-82. [PubMed: 18345450].

29. Rovin JD, Rodgers BM. Pediatric Foreign Body Aspiration. Pediatr Rev. 2000;21(3):86-90. doi:10.1542/pir.21-3-86.
30. Roberts S, Meltzer JA. An evidence-based approach to electrical injuries in children. Pediatr Emerg Med Pract. 2013;10(9):1-16. quiz 16-7. [PubMed: 24191428].

31. Dhopte A, Tiwari VK, Patel P, Bamal R. Epidemiology of pediatric burns and future prevention strategies-a study of 475 patients from a high-volume burn center in North India. Burns Trauma. 2017;5:1 doi: 10.1186/s41038-016-0067-3. [PubMed: 28164140]. [PubMed Central: PMC5286678].

32. Carter PM, Walton MA, Newton MF, Clery M, Whiteside LK, Zimmerman MA, et al. Firearm possession among adolescents presenting to an urban emergency department for assault. Pediatrics. 2013;132(2):213-21. doi: 10.1542/peds.2013-0163. [PubMed: 23837181]. [PubMed Central: PMC3727673].

33. Ruback RB, Shaffer JN, Clark VA. Easy access to firearms: juveniles' risks for violent offending and violent victimization. J Interpers Violence. 2011;26(10):2111-38. doi: 10.1177/0886260510372948. [PubMed: 20724298]

34. Fallahzadeh MA, Salehi A, Hassanzadeh J, Fallahzadeh MH. Epidemiological aspects of acute poisoning in children admitted to a referral hospital during a six-year-period. Ann Pediatr Child Health. 2014;2(3):1020.

35. Ahmed A, AlJamal AN, Mohamed Ibrahim MI, Salameh K, AlYafe $\mathrm{K}$, Zaineh SA, et al. Poisoning emergency visits among children: a 3-year retrospective study in Qatar. BMC Pediatr. 2015;15:104 doi: 10.1186/s12887-015-0423-7. [PubMed: 26315670]. [PubMed Central: PMC4551530].

36. Sheikh S, Hendry P, Lynch S, Kalynych CJ, Aldridge P, Kraemer D. Poisonings with Suicidal Intent Aged 0-21 Years Reported to Poison Centers 2003-12. West J Emerg Med. 2015;16(4):497-502. doi 10.5811/westjem.2015.5.25459. [PubMed: 26265960]. [PubMed Central: PMC4530906].

37. Soori H, Khodakarim S. Child unintentional injury prevention in Eastern Mediterranean Region. Int J Crit Illn Inj Sci. 2016;6(1):33-9. doi: 10.4103/2229-5151.177366. [PubMed: 27051620]. [PubMed Central: PMC4795360].

38. Fowler KA, Dahlberg LL, Haileyesus T, Gutierrez C, Bacon S. Childhood Firearm Injuries in the United States. Pediatrics. 2017;140(1). doi: 10.1542/peds.2016-3486. [PubMed: 28630118].

39. Finkelhor D, Ormrod R. Homicides of Children and Youth. Juvenile Justice Bulletin. 2001.

40. Karbakhsh M, Zargar M, Zarei MR, Khaji A. Childhood injuries in Tehran: a review of 1281 cases. Turk J Pediatr. 2008;50(4):317-25. [PubMed: 19014043].

41. Shakeri A, Jafarizadeh F, Zarenezhad M. [Epidemiology of Suicide Deaths in Fars Province, 2007-2011]. Iran JEpidemiol. 2014;10(1):56-64. Persian. 